\title{
Design and fault tolerant analysis of Five-Phase permanent magnet synchronous motor
}

\author{
Ahmad Sofian Saari, Dahaman Ishak \\ School of Electrical and Electronic Engineering, Universiti Sains Malaysia, Malaysia
}

\begin{tabular}{l}
\hline \hline Article Info \\
\hline Article history: \\
Received, Jan 9, 2019 \\
Revised May 11, 2019 \\
Accepted Jul 28, 2019 \\
\hline
\end{tabular}

\section{Keywords:}

Analytical method

Back-EMF

Finite element analysis

Permanent magnet

Synchronous motor

\begin{abstract}
This paper presents a design of 15-slot/12-pole, five-phase, surface-mounted permanent magnet synchronous motor (PMSM). The five-phase PMSM can be an attractive solution to few applications that demand fault tolerant capability such as in aerospace engineering and electric propulsion. The motor model is first investigated based on the implementation of analytical method. The analytical method derived from the subdomain model of the permanent magnet machine is initially applied to estimate the magnetic flux density distributions for the radial component $\mathrm{Br}$ and the tangential component $\mathrm{Bt}$ in the machine air gap. Other important motor characteristics such as phase back-EMF, line back-EMF, cogging torque and electromagnetic torque are also calculated. The analytically calculated results are then compared with the numerical method in a 2D finite element analysis. Additionally, the capability of this PMSM model against faulty conditions are further investigated. The results show that the analytical model of the 15slot/12-pole, five-phase PMSM provides very accurate motor performance within acceptable error margin. For instance, the average electromagnetic torques, inclusive of the cogging torque, as computed by the analytical and numerical methods are $5.53 \mathrm{Nm}$ and $5.33 \mathrm{Nm}$ respectively, yielding an error of $3.6 \%$. During faulty conditions, the PMSM can possibly continue to operate with lower output torque, about $60 \%$ to $80 \%$ of its rated torque, when one-phase or two phase windings are out of service.
\end{abstract}

Copyright $(2019$ Institute of Advanced Engineering and Science. All rights reserved.

\section{Corresponding Author:}

Dahaman Ishak,

School of Electrical and Electronic Engineering,

Universiti Sains Malaysia, Malaysia.

Email: dahaman@usm.my

\section{INTRODUCTION}

PMSMs certainly have more advantages in terms of power density, higher efficiency and reliability, compact size, and better dynamic performance [1-5]. PMSM is also very popular since its design and constructions can be custom-made in numerous applications according to the performance required. Most conventional PMSMs are built using fundamental AC arrangement of three-phase power supply system. To cater heavy electrical machinery development such as in electrical vehicle (EV), marine propulsion, aircraft and traction applications, the current flow in the machine may require more power consumption in the process [6-7]. Hence, the requirement of employing multi-phase power supply system on PMSM can become foreseeable [8-9].

Multi-phase PMSM is one type of PMSMs designed to function similar as the three-phase PMSM, but with more number of phases to be included and worked in a particular period angle simultaneously [10-11]. PMSM employing multi-phase system has advantages against conventional PMSM three-phase system in terms of lower terminal voltage rating and lower contents of harmonics in the magnetic field distributions in machine air gaps [12-13]. Besides, in terms of performance delivery, multi-phase PMSM supports a better fault tolerance with lower torque ripples and noise characteristic enhancement [14]. 
In fault tolerance and critical load applications, extra countermeasures need to be executed due to any severe error is not permissible and must be minimized to reduce any casualties. To mitigate this concern, reliability on motor power supply need to be upgraded from conventional three phases to a higher number of phases. More than three number of phases in power supply to PM synchronous motor is an advantage in the event that one or two of the phases undergo failure condition.

During fault condition where there were some losses on the phase windings, the present power supplied may differ from the normal condition due to power drop. This affects some performance of the PMSM itself. Even so, the PMSM may not be completely shut down. It is compulsory to sustain the maneuver of the machine within minimal drop of power supply as long as possible to inhibit excessive temperature stress on motor structure. Excessive temperature should be reduced in a certain manner through the cooling arrangements in PMSM body to avoid material stress that can create deformation and damage onto internal and external structure of the PMSM.

This paper is organized as follows: Methodolgy is described in Section 2. In Section 3, research method for the motor model and parameters used in the analytical method is presented. The formulation and derivations of air gap magnetic fields, back-emf waveform, cogging torque and electromagnetic torque are described in Section 4. Results and discussion from the analytical and numerical methods are given in Section 5(a), while performance analysis of the motor during fault conditions is further investigated in Section 5(b). Conclusion and recommendation for future work are finally presented in Section 6.

\section{METHODOLOGY}

Methods for designing the multi-phase PMSM model in this study are classified into two categories: analytical method and numerical method. Each method is able to estimate the overall performances produced by the motor. Each method having its own forte and flaw, e.g. the analytical method can be quite computationally fast once the derivations and source codes have been completed, and very flexible as any modification of the motor dimensions can be easily adjusted [15]. For numerical method based on finite element analysis (FEA), the precision of the software cannot be denied due to high computerization analysis [16-17]. But this high computerization analysis also comes with more computational burden and longer time during motor simulation. However, both methods are suitable in executing motor prediction and performances.

\section{RESEARCH METHOD FOR MOTOR MODEL AND PARAMETERS}

The PMSM model investigated in this paper is envisaged to deploy multi-phase supply system i.e. five-phase which merits fault tolerant capability involving precision safe control on critical load and providing backup during emergencies. The general preferences of PMSM model for the study were an AC motor equipped with five-phase power supply on the windings slotted inside the stator structure. Lesser number of multiphase e.g. four phase, would reduce the backup system for fault tolerance to its minimum where it can withstand to one phase fault only. If more than that, it would deteriorate the motor operation system itself. More multiphase installed e.g. six phase led to increasing manufacturing cost and reducing the reliability of the PMSM design which is known as one of the rugged electrical motor design in the existing electrical machine technologies. Electromagnetic characteristic of PMSM is influenced by number of slot-pole combination as mentioned in [18].

Pole number are selected with regard to motor speed and pole pitch of rotor. For this particular outer diameter of the motor, pole pitch affects the torque performance as high number of poles reduces actual space for magnetic pole pitch. Number of slot is based on multiplication of five since five-phase power supply are implemented. Number of slot should be quite close to the number of pole to minimize the cogging torque. Phase windings will be distributed uniformly into the stator slots. Slot fill factor is typically $40 \%-50 \%$ from the actual size of slot. Conductor size is chosen appropriately to carry the rated current.

Therefore in this case, a five-phase PMSM model with appropriate number of slot-pole combination is proposed in this research work. Inner rotor topology with radial magnetization was favored as to conceal the rotating part of motor for equipment safety purpose. Other reason to do so is to stabilize the operating temperature of stator. The stator windings were built in for definite tolerable temperature and need to gain cooling features through this model. The solution to increase the cooling of the stator windings was by placing it as near as possible to the stator outer yoke.

Before both analytical and numerical methods are conducted, several initial values for the motor parameters should be known as given in Table 1. The volume of the motor model is defined by its cylindrical shape with outer diameter of $110 \mathrm{~mm}$ and axial length of $50 \mathrm{~mm}$. While the tooth tip height, permanent magnet, airgap thickness and copper wire diameter are components located inside the stationary stator. 
Table 1. Motor Dimensions

\begin{tabular}{lc}
\hline \multicolumn{1}{c}{ Parameters } & Values $(\mathrm{mm})$ \\
\hline Axial active length, $l_{a}$ & 50 \\
Stator outer diameter, $D_{o}$ & 110 \\
Stator inside diameter, $D_{i}$ & 56 \\
Tooth tip height, $h_{t}$ & 3 \\
Permanent magnet thickness, $h_{m}$ & 3 \\
Air gap thickness, $h_{g}$ & 1 \\
Diameter of copper wire, $D_{w}$ & 0.5 \\
\hline
\end{tabular}

Motor sizing technique was initially applied to calculate the appropriate dimensions of the fivephase PMSM investigated in this work. Using this technique as described in [19-20], other detailed dimensions and parameters of the PMSM model such as tooth body width, stator yoke height, rotor yoke height, slot depth, slot area and number of winding turns per phase can be estimated quite accurately. Table 2 shows the details of motor dimensions and parameters for the five-phase, 15-slot/12-pole PMSM investigated in this research work.

Table 2. Calculated Parameters of the Motor Model

\begin{tabular}{cc}
\hline Parameters & Values \\
\hline Air gap flux density, $B_{g}$ & $0.829 \mathrm{~T}$ \\
Total flux per stator tooth, $\emptyset_{s p}$ & $0.556 \mathrm{mWb}$ \\
Tooth body width, $W_{t b}$ & $6.6 \mathrm{~mm}$ \\
Thickness of stator yoke, $W_{s y}$ & $3.3 \mathrm{~mm}$ \\
Slot depth, $d_{s}$ & $16.7 \mathrm{~mm}$ \\
Slot area, $A_{\text {slot }}$ & $193.03 \mathrm{~mm}^{2}$ \\
Number of turns per coil, $N_{c}$ & $49 \mathrm{turns}$ \\
Total flux per pole pitch, $\emptyset_{p p}$ & $0.674 \mathrm{mWb}$ \\
Rotor Yoke Height, $W_{r y}$ & $4 \mathrm{~mm}$ \\
Number of coil per phase, $N_{p}$ & 3
\end{tabular}

Information on the investigated PMSM as given in Tables 1 and 2 allows the fundamental assessment of the motor performance based on the analytical formulations and method from previous studies [21-26]. Several important conditions and assumptions were considered when establishing the analytical formulations such as the induced eddy current in rotor, stator and magnets are neglected, non-conductivity and infinitely permeable materials for the stator and rotor cores, linear $\mathrm{BH}$ curve for the magnets, and motor's end effect is neglected.

\section{RESEARCH METHOD FOR MAGNETIC FIELDS, BACK-EMF AND TORQUE}

The implemented analytical method for this research was based on previous study in determining the magnetic flux density of the slotless $2 \mathrm{D}$ analytical subdomain motor model for radial magnetization of the permanent magnet [21-22]. The magnetic flux density in the machine air gap consists of two components i.e. the radial component $\mathrm{Br}$ and the tangential component $\mathrm{B} \Theta$ as given in (1) and (2) respectively. These components are due to the magnetic flux originating from the rotor magnets.

$$
\begin{aligned}
& B_{r}(r, \theta)=\sum_{n=1,3,5 \ldots}^{\infty} K_{B(n)} \cdot f_{B \theta(r)} \cdot \cos n p \theta \\
& B_{\theta}(r, \theta)=\sum_{n=1,3,5 \ldots}^{\infty} K_{B(n)} \cdot f_{B \theta(r)} \cdot \sin n p \theta \\
& f_{B r(r)}=\left(\frac{r}{R_{S}}\right)^{n p-1}\left(\frac{R_{m}}{R_{S}}\right)^{n p+1}+\left(\frac{R_{m}}{r}\right)^{n p+1} \\
& f_{B \theta(r)}=-\left(\frac{r}{R_{S}}\right)^{n p-1}\left(\frac{R_{m}}{R_{S}}\right)^{n p+1}+\left(\frac{R_{m}}{r}\right)^{n p+1} \\
& K_{B(n)}=\frac{\left(\mu_{0} M_{n} \frac{n p}{(n p)^{2}-1}\right)\left((n p-1)+2\left(\frac{R_{r}}{R_{m}}\right)^{n p+1}-(n p+1)\left(\frac{R_{r}}{R_{m}}\right)^{2 n p}\right)}{\left(\mu_{r}+1\right)\left(1-\left(\frac{R_{r}}{R_{S}}\right)^{2 n p}\right)-\left(\mu_{r}-1\right)\left(\left(\frac{R_{r}}{R_{m}}\right)^{2 n p}-\left(\frac{R_{m}}{R_{S}}\right)^{2 n p}\right)}
\end{aligned}
$$


where $\mu_{0}$ is the free-space permeability, $M_{n}$ is the magnet's magnetization vector, $\mathrm{n}$ is number of harmonic iterations, $\mathrm{p}$ is number of rotor pole pairs, $\mu_{r}$ is the relative recoil permeability of the permanent magnet, $R_{r}$ stands for rotor outside radius, $R_{m}$ is magnet outside radius, $R_{s}$ is stator bore radius and $\mathrm{r}$ is the middle airgap radius.

As shown, (1)-(5) facilitate the calculation of magnetic flux density in the machine air gap of slotless stator structure. In order to account for the effect of slotted stator, complex relative air gap permeance function $\lambda$ is used [23] as given by:

$$
\lambda=\frac{k}{s} \frac{w-1}{\sqrt{w-a} \sqrt{w-b}}
$$

where $\mathrm{k}$ is the exponential function of transformation from $\mathrm{T}$ plane to $\mathrm{K}$ plane, $\mathrm{s}$ is the complex variable in $\mathrm{S}$ plane, coefficients $\mathrm{a}$ and $\mathrm{b}$ stand for value of $\mathrm{w}$ at the corner points in $\mathrm{Z}$ plane, and $\mathrm{w}$ is the unknown coefficient along the field solution. Using Maxwell Stress Tensor, the cogging torque Tcog can be predicted via analytical methods [24], given by:

$$
T_{\operatorname{cog}}=\frac{1}{\mu_{0}} l_{a} r^{2} \int_{0}^{2 \pi} B_{s r}(r, \theta) B_{s \theta}(r, \theta) d \theta
$$

where $l_{a}$ is motor's axial length, $\mathrm{r}$ is middle air gap radius, both $B_{\mathrm{sr}}$ and $B_{\mathrm{s} \theta}$ are radial and tangential components of slotted magnetic flux density, and $\theta$ is rotor's angular position.

Phase back-emf in the analytical calculation is determined based on Faraday's Law of electromagnetic induction. The phase back-emf Eph is the negative derivative of flux linkage around the phase winding with respect to time [25-26] as given by:

$$
E_{p h}=-\frac{d \Phi}{d t}
$$

where $\Phi$ is the flux linkage experienced by the phase winding as the rotor rotates. The derivation of magnetic flux linkage over period of time is influenced by rotor synchronous speed, winding factor and radial component Bsr from the analytical subdomain calculation (1)-(5). The output power can be estimated when phase currents Iv are excited into the motor phase windings, assuming that the phase currents are sinusoidal waveform and in phase with their respective phase back-emf Ev.

$$
P_{\text {out }}=\sum_{v=1}^{5} E_{v} I_{v}
$$
speed $\omega \mathrm{m}$

Average output torque Tout is then predicted by dividing the output power with the motor

\section{RESULTS AND DISCUSSION}

The proposed motor of five-phase, 15-slot/12-pole surface-mounted PMSM was analytically calculated for its characteristics and performance, and then compared with the results from the numerical 2D FEA.

\subsection{Motor Characteristics and Performance}

Figure 1(a) shows the magnetic equipotential lines of the five-phase, 15-slot/12-pole PMSM during open-circuit condition. As can be seen, the magnetic fields spread uniformly around the stator core, rotor core and machine air gap, indicating that the unbalanced magnetic pulls (UMP) are zero during open-circuit. The phase winding layouts of this model is shown in Figure 1(b). Each phase winding comprises of three coils which are separated by $120^{\circ}$ mechanical and integrally balanced around the stator periphery. The winding type is a double-layer and single-tooth wound coil, due to the fact that ratio of slot per pole is less than 1.5. Single-layer winding is not feasible since the number of stator slot is an odd number. The first phase winding is marked as A, and sequentially continued to E as the fifth phase. The coils wound around the stator teeth are marked with cross, indicating the GO conductor, and marked with dot, indicating the return conductor. Another important remark to note is that the coils in each phase windings are distributed uniformly around the stator periphery, resulting in symmetrical disposition of the phase windings. Hence, UMP during on-load condition should again be zero. Negligible UMP is a good design merit which will extend the motor bearing life. 


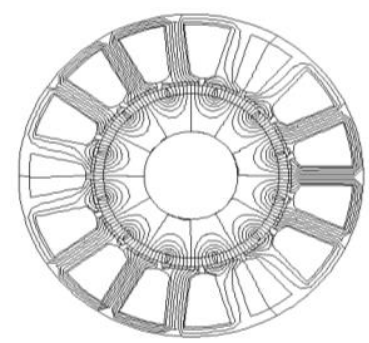

(a)

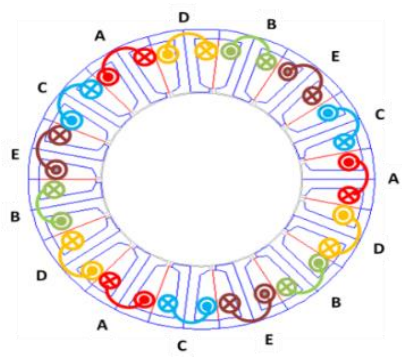

(b)

Figure 1. Five-phase, 15-slot/12-pole PMSM model. (a) Magnetic flux lines (b) Phase winding arrangement

Figure 2 shows the magnetic flux density across the motor area during open-circuit condition. The stator teeth and stator yoke achieve maximum flux density of about $1.49 \mathrm{~T}$ which is just below the saturation limit of $1.5 \mathrm{~T}$ for the $\mathrm{Si}$ steel used in the construction of the stator core. This indicates the stator core has been dimensioned appropriately.

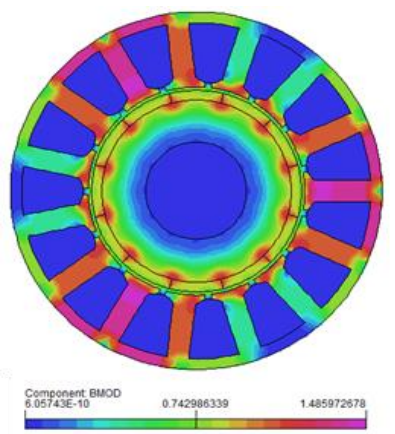

Figure 2. Magnetic flux density as modelled by 2D FEA during open-circuit condition

Comparison of the radial component Bsr of the magnetic flux density in the middle of machine air gap is given in Figure 3. Both results from the analytical and numerical methods show a good agreement. The magnetic flux density waveforms are distorted due to the stator slotting effect. Clearly, the 12-poles of the rotor magnets are visible in this flux density waveform. The positive half-cycles indicate the north polarity, while the negative half-cycles show the south polarity of the magnets. The distortions in the waveform indicate the presence of stator slots. For this motor model, there are fifteen slots with $24^{\circ}$ mechanical pitching distance between them. The complex relative air gap permeance function $\lambda$, used in the analytical method, has managed to capture those stator slotting effect satisfactorily. The magnitude of the radial component Bsr is about $0.81 \mathrm{~T}$, quite appropriate value for typical PMSM with Neodymium magnets mounted on rotor surface.

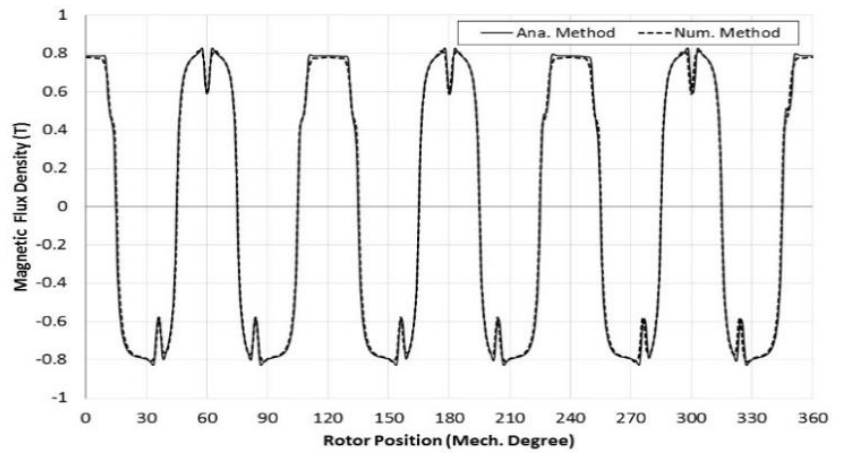

Figure 3. Radial component Bsr of magnetic flux density in the middle of machine air gap

Design and fault tolerant analysis of Five-Phase permanent magnet synchronous... (Ahmad Sofian Saari) 
The tangential components Bs $\theta$ from the analytical and numerical methods computed in the middle of machine air gap are plotted in Figure 4. Again, a good agreement is shown by both methods. All the high peaks of more than $0.3 \mathrm{~T}$ are due to the magnet interpoles. While the small peaks of less than $0.2 \mathrm{~T}$ are present due to the effect of stator slot openings.

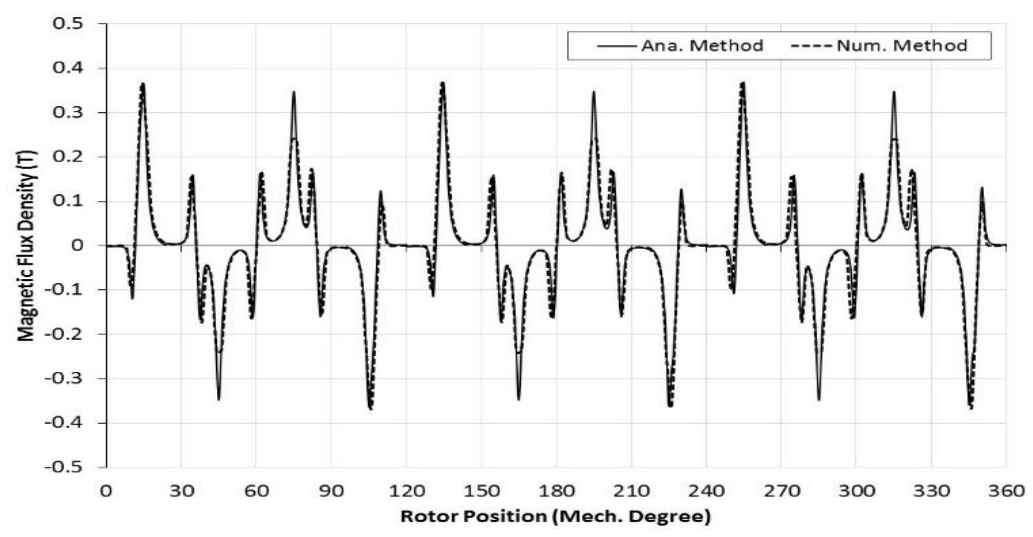

Figure 4. Tangential Component Bs $\theta$ of magnetic flux density in middle of machine air gap

Analytically predicted phase back-emfs are illustrated in Figure 5. The phase back-emf is quite trapezoidal with peak of $19 \mathrm{~V}$. All the five phase back-emfs are balanced and symmetrical with displacement angle of $72^{\circ}$ electrical. The comparison of phase back-emfs between both analytical and numerical methods is shown in Figure 6. It can be noted that the numerically calculated result has approximately the same magnitude of phase back-emf but its trapezaoidal shape is slightly smaller than that of the analytical method. This is possibly due to the flux leakage consideration which has been included into 2D FEA computation, while no flux leakage has been considered in the analytical calculation.

The estimation of cogging torque is shown in Figure 7. For analytical method, the cogging torque reading constantly peaks at $0.345 \mathrm{Nm}$. As validation for the analytical result, the numerical 2D FEA produces similar waveforms with peaks of $0.28 \mathrm{Nm}$. Both results give good agreement. The cogging torque waveform is repeating for every $6^{\circ}$ mechanical. Therefore, in one complete rotor rotation, the motor will experience 60 peaks of cogging torque. During no-load operation, the cogging torque peaks will manifest as motor vibration and acoustic noise. However, during on-load operation, the cogging torque peaks will embed inside the electromagnetic output torque waveform and appear together as torque ripples.

Figure 8 shows the comparison of electromagnetic output torque waveforms between analytical and numerical methods. Analytical method estimates an average torque of $5.53 \mathrm{Nm}$. While the numerical 2D FEA method predicts average torque of $5.33 \mathrm{Nm}$. The margin is about $3.6 \%$. The torque ripples consist of the cogging torque as well as the ripples resulting from the interaction of sinusoidal phase current and phase back-emf harmonics. The numerically predicted waveform of the output torque is slightly smaller than that of analytical method, and this is possibly due to the magnetic flux leakage occurred in the 2D FEA model.

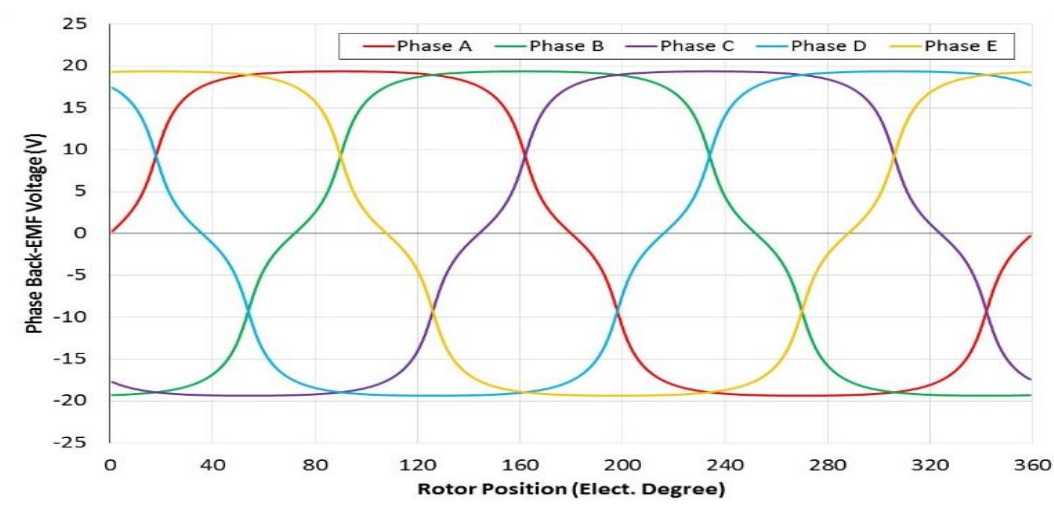

Figure 5. Phase Back-EMFs as predicted by analytical method 


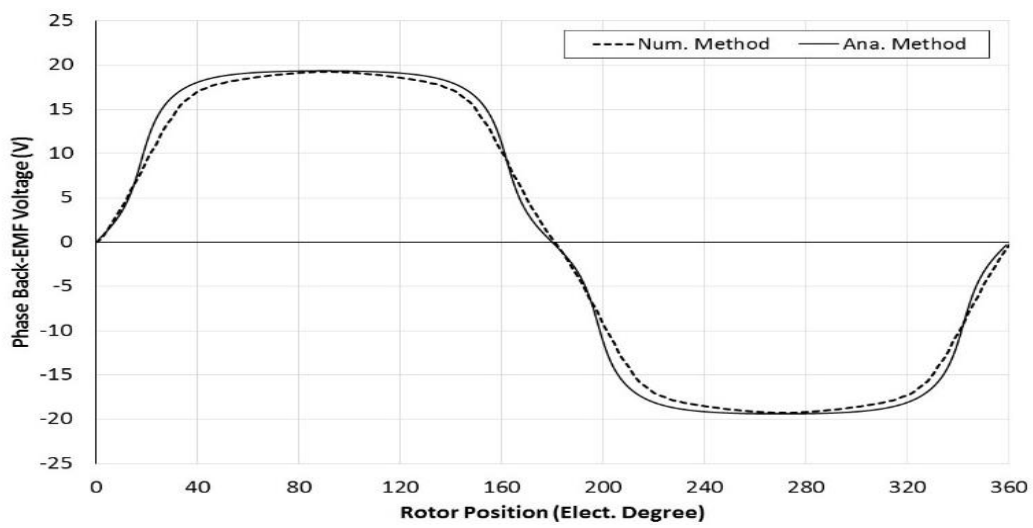

Figure 6. Comparison of phase back-emfs between analytical and numerical methods

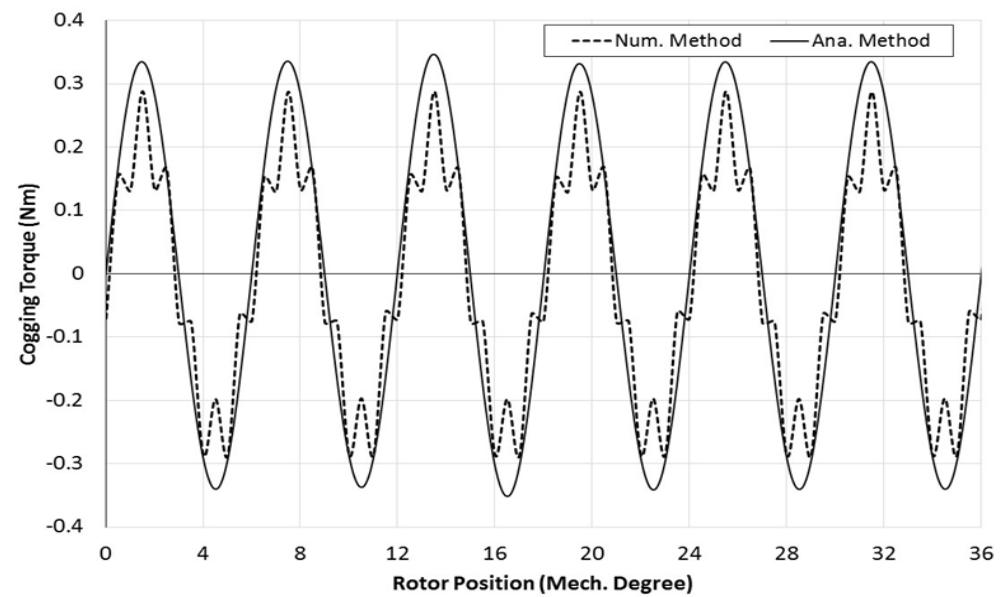

Figure 7. Comparison of cogging torque waveforms from analytical and numerical methods

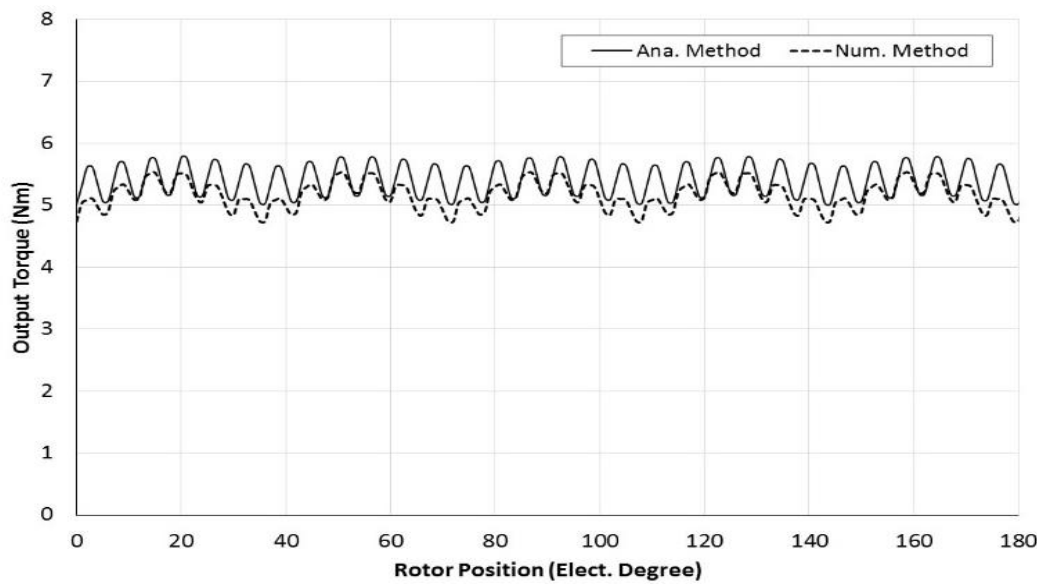

Figure 8. Comparison of electromagnetic output torque between analytical and numerical methods

\subsection{Fault Tolerant Analysis}

In this second part of the results, performance of motor model under fault conditions are presented. The performance on fault test for the motor model is evaluated in both analytical and numerical 2D FEA methods. 


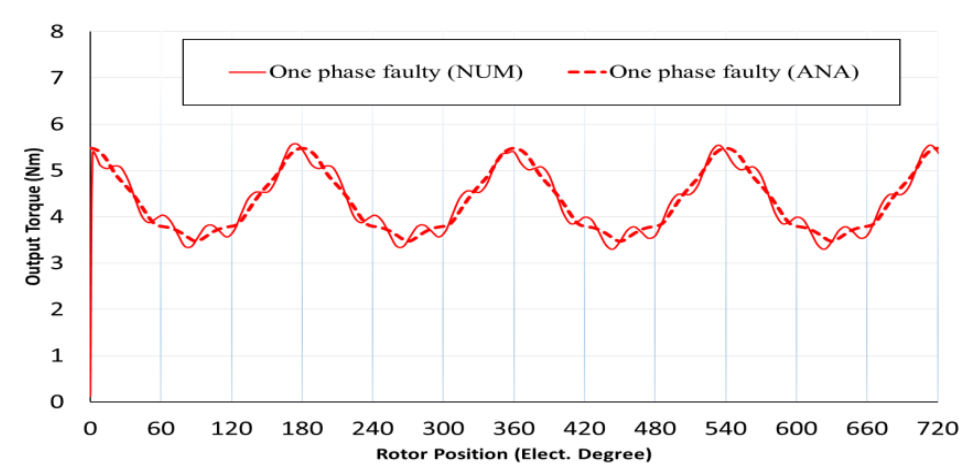

Figure 9. Motor output torque during one-phase faulty operation

Under one-phase faulty operation, one phase winding is considered to be open-circuited, i.e. phase A current is zero. But other phase windings are still healthy and receiving sinusoidal phase currents of 5A peak. Figure 9 shows the motor output torque during this one-phase open fault. The average output torque is about $4.29 \mathrm{Nm}$ with maximum and minimum output torque occurring at $5.57 \mathrm{Nm}$ and $3.30 \mathrm{Nm}$ respectively. From this torque waveform, the high and low peaks appear at every $90^{\circ}$ electrical repetitively. Percentage reduction from the original output torque is about $19.51 \%$, indicating that this reduction represents about onefifth of the original torque from the healthy five-phase PMSM.

Figures 10, 11, 12 and 13 illustrate the motor output torque based on different combinations of twophase open fault i.e. phases A-B, phases A-C, phases A-D, and phases A-E respectively. As can be seen in Figures 10 and 11, the average output torques in two-phase open fault for combinations of phases A-B and A-E are $3.29 \mathrm{Nm}$ and $3.22 \mathrm{Nm}$ respectively. Even so, both torque waveforms are approximately similar in shape and magnitude where the maximum and minimum peaks are about $3.97 \mathrm{Nm}$ and $2.32 \mathrm{Nm}$ respectively. This can be explained based on winding distributions in Figure 1(b) where circumferential distance between phases $\mathrm{A}$ to $\mathrm{B}$ is equal to phases $\mathrm{A}$ to $\mathrm{E}$, i.e. $72^{\circ}$ mechanical. The phase angle seems to be distinct in between both combinations as phases $\mathrm{A}$ to $\mathrm{B}$ is positive, while phases $\mathrm{A}$ to $\mathrm{E}$ is negative, creating leading and lagging phase angle respectively between them.

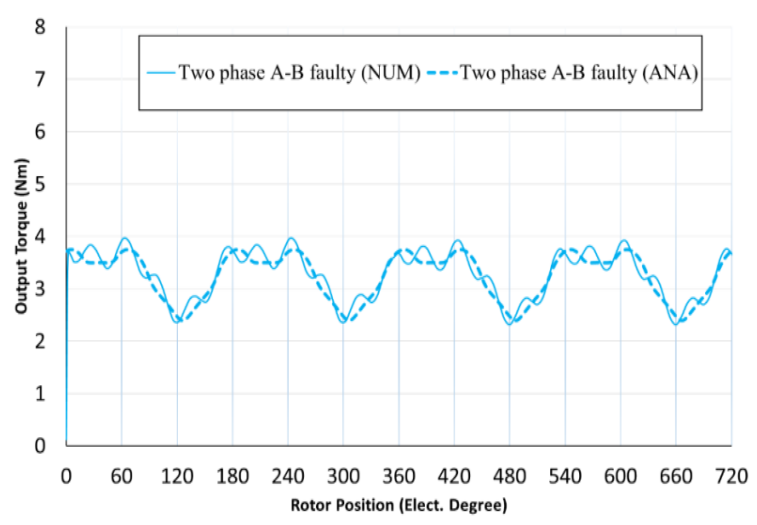

Figure 10. Motor output torque during two-phase faulty operation: phase A and phase B are opencircuited

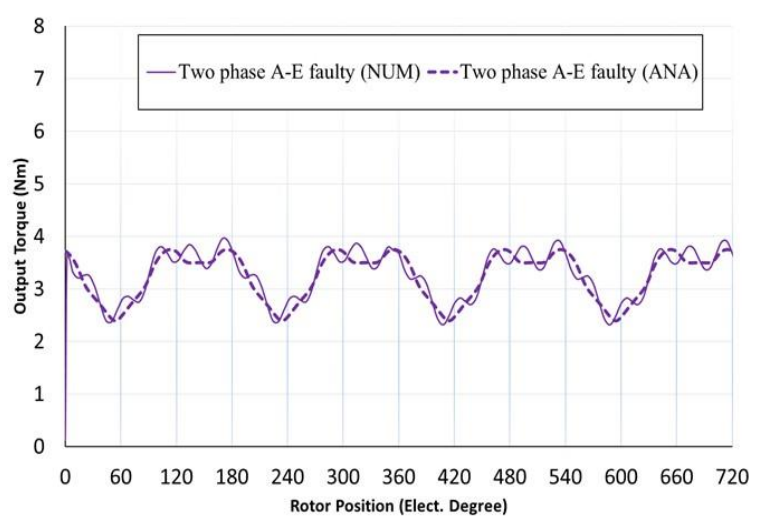

Figure 11. Motor output torque during two-phase faulty operation: phase A and phase E are opencircuited

Similar approach is used to predict the output torque during two-phase open fault for different combinations of phases A-C and phases A-D as shown in Figures 12 and 13, where maximum and minimum peaks are approximately about $4.99 \mathrm{Nm}$ and $1.75 \mathrm{Nm}$ respectively. Both waveforms have almost similar shape with the average torque ranging from $3.19 \mathrm{Nm}$ to $3.31 \mathrm{Nm}$. This is due to the fact that phase A-C has similar circumferential distance to that of phase A-D which is $144^{\circ}$ mechanical, based on winding distribution diagram in Figure 1(b). 


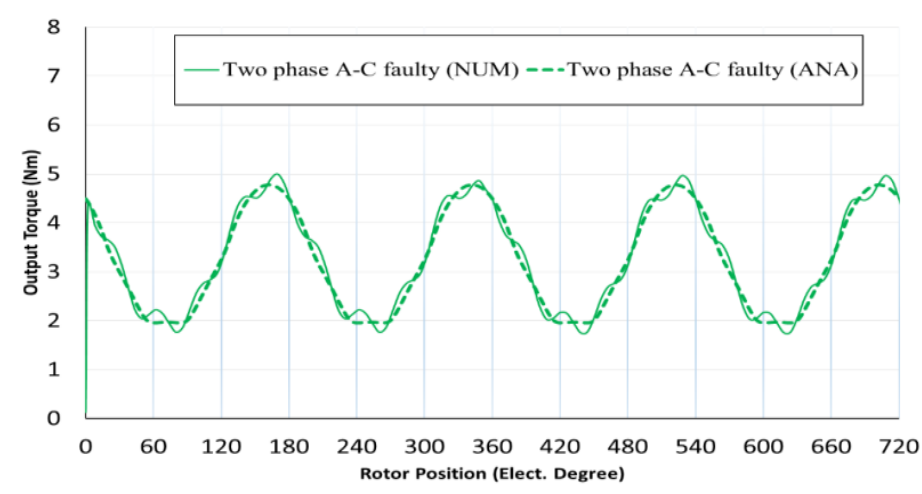

Figure 12. Motor output torque during two-phase faulty operation: phase A and phase C are open-circuited

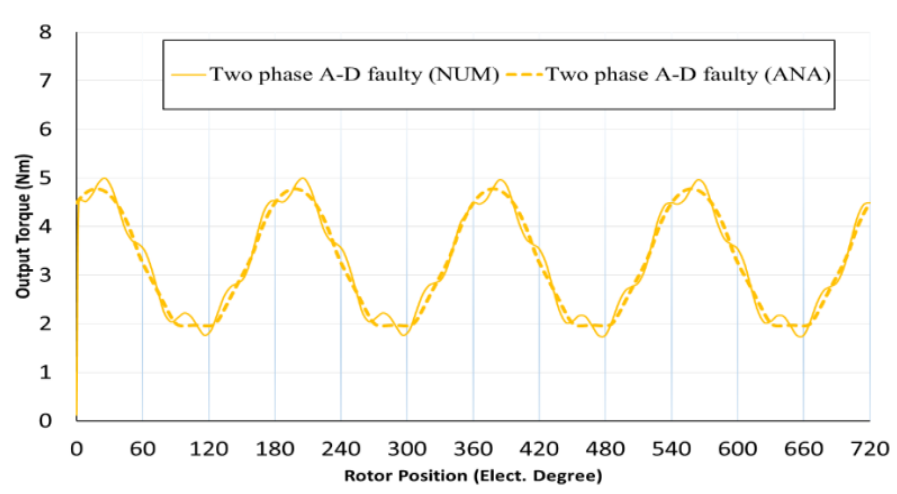

Figure 13. Motor output torque during two-phase faulty operation: phase A and phase D are open-circuited

Table 3 summarises the tolerant adaptability of the proposed five-phase, 15-slot/12-pole PMSM when subjected to one-phase open fault and two-phase open fault. One-phase open fault will result in about $20 \%$ reduction of output torque, albeit the motor is still able to continue operation until further scheduled maintenance. Two-phase open fault predicts that the motor will lose about $40 \%$ of it rated torque, but the average torque is almost similar. Due to winding distribution and layout, the two-phase open fault of phases A-C and A-D exhibits the highest torque ripple of about $100 \%$.

Table 3. Output Torque of the Proposed PMSM Under Faulty Working Conditions

\begin{tabular}{|c|c|c|c|c|c|c|c|}
\hline \multicolumn{2}{|c|}{ Phase Mode } & $\begin{array}{l}\text { Average } \\
\text { Torque }\end{array}$ & $\begin{array}{l}\text { Min. } \\
\text { Torque } \\
(\mathrm{Nm})\end{array}$ & $\begin{array}{l}\text { Max. Torque } \\
(\mathrm{Nm})\end{array}$ & $\begin{array}{c}\text { Torque } \\
\text { Ripple }(\%)\end{array}$ & $\begin{array}{c}\text { Ratio of avg. torque } \\
\text { of each mode to } \\
\text { healthy mode }(\%)\end{array}$ & $\begin{array}{l}\text { Percentage reduction of } \\
\text { ratio between healthy } \\
\text { mode to faulty mode }\end{array}$ \\
\hline \multicolumn{2}{|c|}{$\begin{array}{c}\text { Healthy } \\
\text { One phase fault }\end{array}$} & 5.33 & 5.13 & 5.63 & 9.39 & 100 & 0 \\
\hline \multirow{3}{*}{$\begin{array}{l}\text { Two } \\
\text { phase } \\
\text { fault }\end{array}$} & A-B & 3.29 & 2.32 & 3.97 & 50.15 & 61.73 & 38.27 \\
\hline & A-C & 3.19 & 1.75 & 4.99 & 101.57 & 59.85 & 40.15 \\
\hline & A-D & 3.31 & 1.76 & 5.00 & 104.52 & 62.10 & 37.90 \\
\hline
\end{tabular}

\section{CONCLUSION}

This paper has presented the design and fault tolerant analysis of 15-slot/12-pole, five-phase, surface-mounted PMSM. The five-phase PMSM is typically an attractive solution to few applications that demand fault tolerant capability such as in aerospace engineering and electric propulsion. Based on the investigation and evaluation of the results, it can be concluded that the performance of this five-phase PMSM is confirmed by both analytical and numerical methods. The predictions of air gap magnetic flux density, the cogging torque and the electromagnetic output torque by both the analytical and numerical methods are in good agreement. The analytically computed output torque shows ripples inclusive of the cogging torque. The average electromagnetic torques, inclusive of the cogging torque, as computed by the analytical and 
numerical methods are $5.53 \mathrm{Nm}$ and $5.33 \mathrm{Nm}$ respectively, yielding an error of $3.6 \%$. Furthermore, the fault tolerant analysis shows that this PMSM may continue operation during one-phase open fault and two-phase open fault, albeit its output torque would be reduced. One-phase open fault will result in about $20 \%$ reduction of output torque. Two-phase open fault suffers about $40 \%$ reduction in the output torque. The torque ripple is about $50 \%$ for two-phase open fault of phases A-B and A-E. But it is about $100 \%$ for the two-phase open fault of phases A-C and A-D. Nevertheless, all four different combinations of two-phase open fault, i.e. phases A-B, phases A-C, phases A-D and phases A-E, exhibit almost similar average output torque of about $3.25 \mathrm{Nm}$.

\section{ACKNOWLEDGEMENTS}

The authors would like to thank Universiti Sains Malaysia for providing the financial support under Postgraduate Fellowship and RUI Research Grant (1001/PELECT/8014027).

\section{REFERENCES}

[1] R.G. Shriwastava, M.B. Diagavane, S.R. Vaishnav, "Literature Review of Permanent Magnet AC Motors Drive for Automotive Application,” Bulletin of Electrical Engineering and Informatics (BEEI), Vol. 1, No. 1, pp. 7-14, March 2012.

[2] D. Kumar, G. Ram Das, "Simulation and Analysis of Modified DTC of PMSM", International Journal of Electrical and Computer Engineering (IJECE), Vol. 8, No. 5, pp. 2894-2903, 2018.

[3] G. Ram, K.R. Santha, "Review of Sliding Mode Observers for Sensorless Control of Permanent Magnet Synchronous Motor Drives", International Journal of Power Electronics and Drive Systems (IJPEDS), Vol. 9, No. 1, pp. 46-54, 2018.

[4] M. Yuhendri, A. Ahyanuardi, A. Aswardi, "Direct Torque Control Strategy of PMSM Employing Ultra Sparse Matrix Converter", International Journal of Power Electronics and Drive Systems (IJPEDS), Vol. 9, No. 1, pp. 64-72, 2018.

[5] A. Nori, T. Hassan, "Modeling and simulation of quasi-Z-source indirect matrix converter for permanent magnet synchronous motor drive", International Journal of Power Electronics and Drive Systems (IJPEDS), Vol. 10, No. 2, pp. 882-899, 2019.

[6] X. Chen, J. Hu, K. Chen, Z. Peng, "Modeling of electromagnetic torque considering saturation and magnetic field harmonics in permanent magnet synchronous motor for HEV," Simulation Modelling Practice and Theory, Vol. 66, pp. 212-225, 2016.

[7] Ayman Y. Al-Rawashdeh, "Simulation and analysis of the possibilities of traction electric motor," Indonesian Journal of Electrical Engineering and Computer Science (IJEECS), Vol. 14, No. 1, pp. 51-58, April 2019.

[8] A. Hezzi, S. Ben Elghali, Y. Ben Salem and M. Abdelkrim, "Control of five-phase PMSM for electric vehicle application," $18^{\text {th }}$ International Conference on Sciences and Techniques of Automatic Control and Computer Engineering (STA), pp. 205-211, 2017.

[9] C. Tong, F. Wu, P. Zheng, Y. Sui, L. Cheng, "Analysis and design of a fault-tolerant six-phase permanent-magnet synchronous machine for electric vehicles," 17th International Conference on Electrical Machines and Systems (ICEMS), 2014.

[10] M. Rezal, D. Ishak, "Performance evaluation of multi-phase permanent magnet synchronous motor based on different winding configurations and magnetization patterns", International Journal of Power Electronics and Drive System (IJPEDS), Vol. 10, No. 3, Sep 2019, pp. 1197-1206, 2019.

[11] K. Gaeid, M. Asker, N. Tawfeeq, S. Mahdi, "Computer Simulation of PMSM Motor with Five Phase Inverter Control using Signal Processing Techniques", International Journal of Electrical and Computer Engineering (IJECE), Vol. 8, No. 5, pp. 3697-3710, 2018.

[12] J. Ojeda, H. Bouker, L. Vido, H. Ben Ahmed, "Comparison of 3-phase and 5-phase high speed synchronous motor for EV/HEV applications", 8th IET International Conference on Power Electronics, Machines and Drives (PEMD 2016), 2016.

[13] L. Schreier, J. Bendl and M. Chomat, "Analysis of fault tolerance of five-phase induction machine with various configurations of stator winding," International Conference on Electrical Drives and Power Electronics (EDPE), pp. 196-203, 2015.

[14] Y. Chen, J. Song, J. Zhang and Q. Huang, "Design and analysis of six-phase fault-tolerant PMSM for electric vehicle," Prognostics and System Health Management Conference, pp. 1-6, 2016.

[15] H. Kim, K. Shin, S. Englebretson, N. Frank and W. Arshad, "Analytical model of multiphase permanent magnet synchronous machines for energy and transportation applications," International Conference on Electric Machines \& Drives, pp. 172-179, 2013.

[16] Mohd Luqman M. J et al, "Design and analysis of PM motor with semi-circle stator design using 2D-finite element analysis," Indonesian Journal of Electrical Engineering \& Computer Science (IJEECS), Vol. 13, No. 1, pp. 427-436, 2018.

[17] Tanmoy Dey, Amit Kumar Chowdhury, Sk Mehboob Alam, Surajit Mondal, "Analysis of Six-Phase Interior Permanent Magnet Synchronous Machines for Optimal Parameter Considerations," International Journal of Applied Power Engineering (IJAPE), Vol.7, No.2, pp. 139-146, August 2018. 
[18] S. Raj, R. Aziz, M. Z. Ahmad, "Influence of pole number on the characteristics of permanent magnet synchronous motor (PMSM)," Indonesian Journal of Electrical Engineering and Computer Science (IJEECS), Vol. 13, No. 3, pp. 1318-1323, March 2019.

[19] D. Hanselman, "Brushless permanent-magnet motor design," New York: McGraw-Hill, pp. 125-137, 1994.

[20] P.Srinivas, "Design and FE Analysis of BLDC Motor for Electro-Mechanical Actuator," Journal of Electrical Systems, Vol. 11, No. 1, pp. 76-88, 2015.

[21] A. Rahideh and T. Korakianitis, "Analytical calculation of open-circuit magnetic field distribution of slotless brushless PM machines," International Journal of Electrical Power \& Energy Systems, Vol. 44, No. 1, pp. 99-114, 2013.

[22] Z. Zhu, D. Howe and C. Chan, "Improved analytical model for predicting the magnetic field distribution in brushless permanent-magnet machines," IEEE Transactions on Magnetics, Vol. 38, No. 1, pp. 229-238, 2002.

[23] D. Zarko, D. Ban and T. Lipo, "Analytical calculation of magnetic field distribution in the slotted air gap of a surface permanent-magnet motor using complex relative air-gap permeance," IEEE Transactions on Magnetics, Vol. 42, No. 7, pp. 1828-1837, 2006.

[24] D. Zarko, D. Ban and T. Lipo, "Analytical Solution for Cogging Torque in Surface Permanent-Magnet Motors Using Conformal Mapping," IEEE Transactions on Magnetics, Vol. 44, No. 1, pp. 52-65, 2008.

[25] Y. Oner, Z. Zhu, L. Wu, X. Ge, H. Zhan and J. Chen, "Analytical On-Load Subdomain Field Model of PermanentMagnet Vernier Machines,” IEEE Transactions on Industrial Electronics, Vol. 63, No. 7, pp. 4105-4117, 2016.

[26] M. Rahman, K. Kim and J. Hur, "Design and Optimization of Neodymium-Free SPOKE-Type Motor with Segmented Wing-Shaped PM,” IEEE Transactions on Magnetics, Vol. 50, No. 2, pp. 865-868, 2014. 